\title{
Editorial - Revista Científica: eletrônica e/ou impressa?
}

Desde o advento da Internet que, entre outras funções, tem se constituído como um grande repositório mundial de informações se discute o futuro do livro impresso face às publicações eletrônicas. Dentre as várias perspectivas do livro discutidas por pensadores tais como Derrida (2003) e Chartier (2002) o que vem se configurando é a coexistência de ambas as formas de divulgação, cada qual com suas especificidades.

Poderíamos então perguntar qual o futuro das revistas científicas impressas nessa mesma conjuntura?

No Brasil assistimos a um grande esforço de publicização da íntegra dos artigos das revistas científicas na Internet de modo gratuito. Em 1997, foi criado A Scientific Electronic Library Online - Scielo, desenvolvida em parceria com Fapesp, Bireme (Centro Latino-Americano e do Caribe de Informação em Ciências da Saúde) e CNPq. Seu acervo atual é de 175 títulos. Os artigos da Revista Psicologia \& Sociedade fazem parte da coleção Scielo a partir do número 14 (1).

Tomando como base a filosofia e a metodologia Scielo a Biblioteca Virtual em Saúde - Psicologia (BVS-Psi) e a Associação Brasileira de Editores Científicos de Psicologia - ABECiP lançaram o Pepsic - Periódicos eletrônicos em Psicologia. A área da psicologia afirma assim seu propósito em avançar nos processos de publicação eletrônica.

Além de disponibilizar de forma gratuita o conteúdo das revistas, existem programas que também possibilitam realizar as atividades de editoração de periódicos científicos pela Internet. O Sistema Eletrônico de Editoração de Revistas (SEER), traduzido e customizado pelo Instituto Brasileiro de Informação em Ciência e Tecnologia (IBICT) é um exemplo disso. Nossa revista utiliza esse software desde novembro 2005. O gerenciamento eletrônico do processo editorial agrega agilidade, mobilidade e reduz substancialmente os custos de circulação de material, diminuindo o consumo e o armazenamento de papéis. Mas uma de suas principais funcionalidades é facilitar a colaboração de editores associados de diferentes pontos geográficos. Foi após sua utilização que conseguimos trabalhar com uma comissão editorial que agrega pesquisadores de diferentes estados da federação. Utilizando essa mesma ferramenta disponibilizamos os conteúdos das Revistas Psicologia \& Sociedade também pelo site: www.ufrgs.br/ revistapsicologiaesociedade.

Frente a todas essas considerações estariam as revistas científicas impressas com seus dias contados? Penso que devemos tomar com mais vagar essa conclusão. Um primeiro aspecto a considerar é que estamos ainda em uma etapa inicial de interação com as tecnologias digitais e nessa condição é comum adaptarmos velhos processos às novas técnicas. Tal como muitos iniciaram utilizando os editores de texto para datilografar documentos e só paulatinamente foi se alterando o modo de interação no qual os editores de textos eram utilizados para produzir o documento. Da mesma forma pergunto se não estamos, de certo modo, adaptando a forma - revista impressa - na Internet? Que outras formas podemos propor para publicações científicas eletrônicas? Certamente existem funcionalidades diversas que poderão diferenciar as peculiaridades de cada modalidade de publicação a serem exploradas, inventadas.

Decorre dessa diferenciação que as novas tecnologias não suplantam as anteriores, provocam, é certo, modificações. Assim se constituem espaços interativos e de produção frente aos quais uma ou outra modalidade pode ser mais interessante, ao cumprir funções distintas. Penso, por exemplo, que a Revista Psicologia \& Sociedade ao chegar à casa de cada sócio da ABRAPSO atualiza um coletivo de pertencimento, que parece não ocorrer quando a acessamos pela Internet.

Certamente esse é um debate em aberto, gostaria de me aliar aos que defendem a manutenção das duas modalidades de divulgação, encorajando à invenção de suas especificidades, diferenciando formatos, usos e relações com o objetivo de tornar mais acessível o conhecimento científico.Nessa perspectiva seguimos publicando Psicologia \& Sociedade nos dois formatos.

Abrimos o primeiro número de 2007 com o trabalho de Mary Jane Spink intitulado Pesquisando no cotidiano: recuperando memórias de pesquisa em Psicologia Social. De início a autora sustenta a posição de pesquisador implicado na utilização da idéia de um pesquisar "no" cotidiano e não pesquisar "o" cotidiano. A partir de três estudos recupera e discute modos de pesquisa que nasceram de práticas de psicólogos sociais, atualizando questões metodológicas e políticas da pesquisa. Seu estudo ensina a densidade da história da própria Psicologia Social, muitas vezes desconsiderada. Seguindo a temática metodológica o artigo $O$ funcionamento da atenção no trabalho do cartógrafo de Virgínia Kastrup trata da questão da atenção na etapa inicial do trabalho do cartógrafo. Com sua discussão podemos compreender o quanto a observação é implicada e também um ato criativo. Permanecendo ainda na temática metodológica, Kátia Maheirie e Kelly Bedin França no artigo Vygotski e Sartre: aproximando concepções metodológicas na construção do saber psicológico apontam posições teóricas e políticas de ambos autores que influenciam os modos de pesquisar.

Oswaldo Hajime Yamamoto no artigo Políticas sociais, "terceiro setor" e "compromisso social": perspectivas e limites do trabalho do psicólogo ao defender a legitimidade e a necessidade do trabalho do psicólogo no campo do bem-estar público, alerta que isso por si só não representa um indicador do compromisso social. Um exemplo desse tipo de trabalho é tratado no artigo Sujeitos no sumidouro: a experiência de criação e resistência do jornal Boca de Rua. Danichi Hausen Mizoguchi e colaboradores, mesmo sem tratar explicitamente do trabalho do 
psicólogo, propõem como um jornal confeccionado por moradores de rua, apoiado por uma Ong, pode constituirse em um espaço de resistência urbana, mídiática e de consumo, na contramão de alguns dos valores neo-liberais, frente aos quais algumas práticas psi podem estar atreladas.

A interface entre drogas e sociedade é abordada em dois artigos. Liliana A. M. Guimarães e Sonia Grubits no artigo Alcoolismo e violência em etnias indígenas: uma visão crítica da situação brasileira fazem um levantamento dos principais estudos epidemiológicos sobre alcoolismo no Brasil, apontando a necessidade de um maior número de estudos nessa temática e, principalmente, criticam a falta de atenção para as especificidades que o uso do álcool tem em cada etnia. Em outro artigo intitulado Maconha e contexto familiar: um estudo psicossocial entre universitários do Rio de Janeiro, Violeta Martins Ferreira e Edson A. de Sousa Filho encontraram diferenças no modo como universitários - usuários e não usuários de maconha - apresentam seus familiares.

Questões relativas ao trabalho aparecem em três artigos. No primeiro deles, intitulado $A$ saúde e os processos de trabalho no capitalismo: reflexões na interface da Psicodinâmica e da Sociologia do Trabalho, Alvaro Roberto Crespo Merlo e Naira Lima Lápis discutem os processos de trabalho e o adoecimento. Para os autores as mudanças promovidas pela implementação do modelo de gestão japonês, longe de resolver os problemas causados pela separação concepção-execução do trabalho, ampliam as exigências aos trabalhadores tornando-se fonte de novos adoecimentos. Concimar da Silva Lopes e colaboradores tratam do trabalho das profissionais do sexo no artigo $A$ bela adormecida: estudo com profissionais do sexo que atendem à classe média alta e alta na cidade de Goiânia. Revelam que o que parecia conflitante aos olhos das pesquisadoras não era da mesma forma significado por essas mulheres. As entrevistadas sustentam a posição de mercadoria, sem que isto resulte em maiores conflitos internos. No artigo Empreendedorismo feminino: tecendo a trama de demandas conflitantes, Eva G. Jonathan e Taissa M. R. da Silva discutem as estratégias que donas de negócios utilizam em relação aos conflitos no espaço do trabalho, entre demandas familiares e profissionais e entre demandas do trabalho e pessoais. Para as autoras a resolução desses conflitos possibilitam transformações nos contextos familiar, profissional e pessoal.

A interface com a educação é tratada em três trabalhos. Jorge Castellá Sarriera e colaboradores apresentam o artigo A relação entre pesquisadores e escolas públicas: um diálogo a partir do tempo livre. O transcurso de ações desenvolvidas em um projeto de pesquisa possibilitou aos autores constituir um espaço entre universidade e escola propício para debater temas que geralmente não são tratados dentro dos espaços institucionais, tais como, controle das instituições dirigido aos alunos; a passividade destes nas suas escolhas pessoais; o estranhamento das escolas diante do novo, daquilo que coloca em risco sua autoridade e poder e as expressões e atitudes destes adolescentes uma vez inseridos numa prática reflexiva. No artigo Violência, sociedade e escola: da recusa do diálogo à falência da palavra, Érika Cecília Soares Oliveira e Sueli Terezinha Ferreira Martins discutem alguns dos efeitos da ausência de espaços comunicativos na escola. Segundo as autoras, a dificuldade de constituição desses espaços comunicativos propicia a emergência de atos violentos, demonstrando a ineficácia de uso da palavra. Um contra-exemplo é o trabalho de Maria Helena De-Nardin e Regina Orgler Sordi, intitulado Um estudo sobre as formas de atenção na sala de aula. As autoras analisam especificidades das relações estabelecidas entre professoraluno propícias a construção de um espaço de comunicação dialógica o qual favorece a capacidade atentiva dos alunos. O artigo apresenta relação teórica com o de Virgínia Kastrup, publicado nessa mesma edição. No artigo, Ecolha profissional e dramática do viver adolescente, Maria Auxiliadora Barreto e Tania Aiello-Vaisberg buscam caracterizar aspectos do imaginário social sobre a adolescência contemporânea ao investigar as concepções de estudantes de Psicologia e Pedagogia sobre o adolescente em vias de escolha da profissão, discutindo a dúvida o desejo parental e a falta de confiança em si.

Encerra esse número a resenha do livro As Marcas do Humano de Angel Pino feita por Alice Casanova.

Antes de concluir esse editorial gostaria de convidar a todos os leitores para participar XIV Encontro Nacional da ABRAPSO - Associação Brasileira de Psicologia Social, ocorrerá dos dias 31 de outubro de 2007 a 03 de novembro de 2007 na UERJ, Rio de Janeiro. O tema geral do Encontro é DIÁLOGOS EM PSICOLOGIA SOCIAL. Certamente é mais um dos momentos para o exercício da palavra, ou de como nosso fazer (nossas pás) lavram (inventam) uma Psicologia Social. Grata Elida Tessler pela bela inspiração da capa.

Cleci Maraschin

Editora

\section{Referências}

Charitier, R. (2002) Os desafios da escrita.São Paulo, Editora Unesp. Derrida, J. ( 2003 ) Papier Machine. Paris, Galilée. 